\title{
Assessment of fibrotic burden among chronic hepatitis $B$ virus-infected patients with normal transaminase level
}

\author{
Mi Young Jeon ${ }^{1,2,3}$, Beom Kyung Kim,2,3 and Seung Up Kim¹,2,3 \\ 'Department of Internal Medicine and ${ }^{2}$ Institute of Gastroenterology, Yonsei University College of Medicine, Seoul; ${ }^{3}$ Yonsei Liver Center, \\ Severance Hospital, Seoul, Korea
}

Keywords: Hepatitis B virus; Liver fibrosis; Elastography; Classification

\section{See Article on Page 384}

Given that elevated serum levels of hepatitis B virus (HBV) DNA are associated with an increased risk for liver cirrhosis or hepatocellular carcinoma ( $\mathrm{HCC}){ }^{1}$ the mainstay of hepatitis B treatment is antiviral therapy (AVT) to suppress viral replication. Currently, commencement of AVT depends on not only serum HBV-DNA level but also serum alanine aminotransferase (ALT) level, hepatitis B e antigen status, and the presence of liver cirrhosis or $\mathrm{HCC}^{2,3}$ However, even in cases with normal transaminase levels, patients with high HBV-DNA and histologically proven necro-inflammation or fibrosis ( $\geq F 2$ grade) may be candidates for AVT, with the goal of minimizing disease progression.

As reported in the most recent issue of Clinical Molecular and Hepatology, Cristina et al. ${ }^{4}$ found that approximately $14 \%$ of subjects with chronic HBV infection and normal transaminase levels had significant liver fibrosis ( $\geq 7.9 \mathrm{kPa}$ ), as assessed by transient elastography (TE). However, there was concern as to whether patients with well-controlled inflammation may still experience dis- ease progression. In this article, we address several of the abovementioned concerns.

First, in considering that the enrolled subjects tended to be more obese (mean body mass index $27 \pm 5 \mathrm{~kg} / \mathrm{m}^{2}$ ) compared to previous studies, ${ }^{5,6}$ they were more likely to have concomitant liver disease other than chronic HBV infection. ${ }^{7.8}$ Obesity is strongly associated with fatty liver disease and metabolic syndrome, both of which can accelerate hepatic fibrosis. ${ }^{8,9}$ Steatohepatitis proven on histology may exist even in cases of normal baseline transaminase levels, which suggests that elevated ALT is not predictive of necro-inflammation or fibrosis. The suggestion that patients with altered transaminases are more likely to have a higher fibrotic burden implies that this cohort should include patients with steatohepatitis with, at a minimum, indolent histological activity. Furthermore, increased organ fat can lead to an overestimation of liver stiffness in some patients. ${ }^{10}$ Taken together, these findings suggest that combined fatty liver disease with hepatic necro-inflammation, even in the presence of "normal" transaminase levels, may result in a higher proportion of patients with fibrosis in this cohort.

\section{Abbreviations:}

ALT, alanine aminotransferase; AVT, antiviral therapy; HBV, hepatitis B virus; HCC, hepatocellular carcinoma; IT, immune tolerant; $\mathrm{TE}$, transient elastography

\section{Corresponding author : Seung Up Kim}

Department of Internal Medicine, Yonsei University College of Medicine, 50-1 Yonsei-ro, Seodaemun-gu, Seoul 03722, Korea

Tel: +82-2-2228-1994; Fax: +82-2-393-6884

E-mail:ksukorea@yuhs.ac

https://orcid.org/0000-0002-9658-8050 
Second, Cristina et al. ${ }^{4}$ defined significant fibrosis as stage $\geq F 2$ $(\geq 7.9 \mathrm{kPa}$ ) using TE. Although the presence of significant fibrosis is considered a hallmark of progressive disease, the diagnostic performance of TE in classifying patients as F2 or higher is relatively limited. Receiver operating characteristic for $\geq F 2$ was highly variable in a recent meta-analysis, ranging between $68 \%$ and $100 \%{ }^{11}$ Therefore, TE alone is insufficient in clinical practice, especially in the diagnosis of grades $\mathrm{FO}-2$. Furthermore, it has been suggested that validated biomarker testing (i.e., FibroTest) is superior in differentiating F0 vs. F1 vs. F2. ${ }^{12}$

Lastly, Cristina et al. ${ }^{4}$ allocated study participants only when normal transaminase levels were maintained over 3 consecutive tests for 9 months. However, viral phases are subject to change depending on the various interactions between host immunity and viral replication. As such, viral phases are not necessarily sequential, ${ }^{13}$ and the duration of 9 months used to define normal transaminase levels might in fact be insufficient. Kim et al. ${ }^{14}$ recently demonstrated that untreated immune tolerant (IT) phase patients with normal transaminase levels are also subject to a significant risk for disease progression. This study may be subject to similar criticism, because IT-phase patients were defined through only 1 year of observation. Taken together, these results indicate that patients classified as having well-controlled inflammation at baseline may eventually shift to an immune-active status over an extended clinical course. As such, viral and biochemical status should be continuously tracked during the follow-up.

Although AVT is recommended in patients with significant fibrosis as proven by liver biopsy even in those with normal ALT level, ${ }^{2,3}$ it is not always feasible to perform biopsies depending on the presence of fibrosis. Therefore, noninvasive surrogates for liver fibrosis such as TE, shear wave elastography, or magnetic resonance imaging, all of which are more accurate than ultrasound in assessing the overall fibrotic burden, may be required to identify the optimal candidates for AVT among chronic hepatitis B patients with normal transaminase levels. ${ }^{7,15}$ As Cristina et al. ${ }^{4}$ described, the use of noninvasive imaging surrogates may be necessary to identify chronic HBV patient subgroups where AVT could potentially reduce the risk of disease progression.

In conclusion, the study by Cristina et al. ${ }^{4}$ confirm that a thorough assessment of liver fibrosis is required to stratify subgroups of patients with normal transaminase levels, to select optimal candidates for AVT, when histological information is not available.

\section{Authors' contribution}

S.U. Kim designed this study. M.Y. Jeon and B.K. Kim wrote the manuscript. All authors contributed to the revision of the manuscript.

\section{Conflicts of Interest}

The authors have no conflicts to disclose.

\section{REFERENCES}

1. Chen CJ, Yang HI, Su J, Jen CL, You SL, Lu SN, et al. Risk of hepatocellular carcinoma across a biological gradient of serum hepatitis $B$ virus DNA level. JAMA 2006;295:65-73.

2. European Association for the Study of the Liver. EASL 2017 Clinical Practice Guidelines on the management of hepatitis B virus infection. J Hepatol 2017;67:370-398

3. Terrault NA, Lok ASF, McMahon BJ, Chang KM, Hwang JP, Jonas $M M$, et al. Update on prevention, diagnosis, and treatment of chronic hepatitis B: AASLD 2018 hepatitis B guidance. Hepatology 2018;67:1560-1599.

4. Cristina SJL, Marta CM, Mercedes GS, Almudena PM, Álvaro HM, Luis VSJ, et al. Characterization and evaluation of liver fibrosis grade in patients with chronic hepatitis B virus infection and normal transaminases. Clin Mol Hepatol 2018;24:384-391.

5. Zhu L, Jiang J, Zhai X, Baecker A, Peng H, Qian J, et al. Hepatitis $B$ virus infection and risk of non-alcoholic fatty liver disease: a population-based cohort study. Liver Int. 2018 Jul 19. doi: 10.1111/ liv.13933.

6. Wong VW, Wong GL, Chu WC, Chim AM, Ong A, Yeung DK, et al. Hepatitis B virus infection and fatty liver in the general population. J Hepatol 2012;56:533-540.

7. Fan JG, Kim SU, Wong VW. New trends on obesity and NAFLD in Asia. J Hepatol 2017;67:862-873.

8. Wong GL, Wong VW, Choi PC, Chan AW, Chim AM, Yiu KK, et al. Metabolic syndrome increases the risk of liver cirrhosis in chronic hepatitis B. Gut 2009;58:111-117.

9. Mofrad P, Contos MJ, Haque M, Sargeant C, Fisher RA, Luketic VA, et al. Clinical and histologic spectrum of nonalcoholic fatty liver disease associated with normal ALT values. Hepatology 2003;37:12861292.

10. Petta S, Maida M, Macaluso FS, Di Marco V, Cammà C, Cabibi D, et al. The severity of steatosis influences liver stiffness measurement in patients with nonalcoholic fatty liver disease. Hepatology 2015;62:1101-1110.

11. Friedrich-Rust M, Ong MF, Martens S, Sarrazin C, Bojunga J, Zeuzem $S$, et al. Performance of transient elastography for the staging of liver fibrosis: a meta-analysis. Gastroenterology 2008;134:960-974.

12. Poynard T, Morra R, Halfon P, Castera L, Ratziu V, Imbert-Bismut F, 
Mi Young Jeon, et al. Liver fibrosis stratification in patients with hepatitis B

et al. Meta-analyses of FibroTest diagnostic value in chronic liver disease. BMC Gastroenterol 2007;7:40.

13. Brunetto MR, Oliveri F, Coco B, Leandro G, Colombatto P, Gorin JM, et al. Outcome of anti-HBe positive chronic hepatitis $B$ in alphainterferon treated and untreated patients: a long term cohort study. J Hepatol 2002;36:263-270.

14. Kim GA, Lim YS, Han S, Choi J, Shim JH, Kim KM, et al. High risk of hepatocellular carcinoma and death in patients with immunetolerant-phase chronic hepatitis B. Gut 2018;67:945-952.

15. Jung KS, Kim SU, Ahn SH, Park YN, Kim DY, Park JY, et al. Risk assessment of hepatitis B virus-related hepatocellular carcinoma development using liver stiffness measurement (FibroScan). Hepatology 2011;53:885-894. 